\title{
sciforum
}

Conference Proceedings Paper

\section{A Satellite View of the Atmospheric Dry Intrusion and its Influences on the Mid-Latitude Disastrous Weather}

Published: 15 July 2016

Yi-Xuan Shou ${ }^{1, *}$, Feng $\mathrm{Lu}^{1}$ and Shaowen Shou ${ }^{2}$

1 National Satellite Meteorological Center, China Meteorological Administration, Beijing 100081, China; lufeng@cma.gov.cn

2 Nanjing University of Information Science \& Technology, Nanjing 210044, China; sshou999@126.com

* Correspondence: yshou@atmos.umd.edu; Tel.: +86-301-273-5507

\begin{abstract}
Dry intrusion is an important mid-latitude atmosphere phenomenon within the upper troposphere and lower stratosphere. It is always found to be related to the cyclogenesis, rainstorm, as well as convection generation and precipitation enhancement. Since the atmosphere environment for any of these above-mentioned weather is terribly complicated, those preexisting popular schemes which takes no account of water vapor may not suitable for detecting the dry intrusion related to these weathers. With regard to the merits and demerits of the current preexisting schemes, a new scheme based on Fengyun-2E geo-stationary satellite data is presented in this study to detect the atmospheric dry intrusion. The scheme is set up based on the statistical relationship between water vapor at high level troposphere, the general moist potential vorticity, ozone concentration and upper-level jet. After using the total amount of ozone and ozone profile operational products retrieved by Fengyun-3 Polar Orbiting Meteorological Satellites and the potential vorticity calculated by ECMWF Interim data for validation, this scheme is applied to analyze two typical middle-latitude weather processes. One is the famous Beijing extreme rainfall of 21 July 2012 and the other is a hailstorm occurred on the eastern China during March 19, 2014. A good application effect in both cases suggests that our new method of detecting dry intrusion is feasible and can be helpful in middle-latitude disastrous weather monitoring and forecasting.
\end{abstract}

Keywords: dry intrusion; Stratosphere-troposphere exchange; mid-latitude, satellite

\section{Introduction}

Stratosphere-troposphere exchange is always described as a dynamical, chemical and radiative coupling process of the material of the lowest two layers of the atmosphere. Their crucial interplay with convection and fast transport of the chemical materials have therefore attracted widespread attention in the research community since it is first found by Reed (1955), with scientists having carried out a large amount of observation experiments on it since 2005 in particular. The process of air mass passively moving from stratosphere to troposphere is always called as tropopause folding or dry intrusion since the air mass within stratosphere is relatively dry and has a high potential vorticity value and ozone concentration. As documented by the previous studies, the intensity and evolution of dry intrusion can be treated as important indices in forecasting the severe weather over mid-latitude region since it always suggests frontogenesis at upper level which will impact on the development of convective cloud and the further convection [1]. To precisely estimate the intensity 
The 1st International Electronic Conference on Atmospheric Sciences (ECAS 2016), 16-31 July 2016;

Sciforum Electronic Conference Series, Vol. 1, 2016

and predict the evolution of the dry intrusion, so far several methods based on diagnosis and modeling or their combinations are developed.

The diagnosis method can be further divided into two categories with one that based mainly on the conventional observations (such as, rawinsonde, radiosonde etc.) and the other that on the basis of remote sensing techniques. Since the former diagnosis method is always limited by the temporal and spatial resolution, it has been rarely used directly for estimation nowadays but for validation instead [2-4]. Since 1960 when the first weather satellite successfully launched, satellite observations are used widespread in various perspectives. Among them the upper atmospheric study is found to most benefit from satellites over the rest fields due to their top-down view angle characteristics and some specific properties of their channels. For the dry intrusion, it is always found in the water vapor (WV) channels of weather satellite due to the sensitivity of the irradiance of these channels to the water content over the upper troposphere [5]. For example, the peak value of the weighting functions of the WV channel (the center wavelength is of $6.7 \mu \mathrm{m}$ ) of Fengyun-2E geostationary weather satellite is located around $400 \mathrm{hPa}$ which means air parcels with low moisture will hardly be seen by this channel of the satellite. On the satellite images, these areas will be shown as some dark areas with high brightness temperature. Based on this property, the second diagnosis method of dry intrusion that based on the given brightness temperature of the WV channels is developed. Due to its ease of implementation and having a relatively high consequence on temporal and spatial scales, this method is currently used more often. While one may find that a numerous of erroneous or missed detections may occur by merely using a simple threshold value. For example, the dark areas on the WV channel images are always observed over the Sahara, Indian and Arabian deserts around the Tropic of Cancer. While they are formed due to the low moisture content within the whole atmospheric column over these areas other than the stratospheric dry intrusion. On the other hand, some intense dry intrusions that occurred over the high latitude areas may have a relatively low brightness temperature or shown brighter on the cloud images than that observed over the low latitude areas due to the lower temperature. And in such situation, the boundary between the dry and moisture air is always blurred and hard to be detected. Besides, it was documented by Roger and Holmes [5], seasonal variation could also be a factor which would impact the accuracy of the dry intrusion detection on satellite images. Therefore, the diagnosis based on brightness temperature of WV channels is also not an optimized method for detecting dry intrusion in atmosphere.

Numerical modeling is another popular method that used for detecting dry intrusion. It is developed with the development of high-resolution numerical models [6]. This method is better than the diagnosis that based on conventional observations due to its high spatial and temporal resolution. But sometimes scientists find the relation between the modeling dry intrusions and the observational ones are weak $[7,8]$ which makes people often speculate the modeling results.

Considering the pros and cons, a combination of the diagnosis on the basis of remote sensing techniques and modeling is developed. The main idea of this method is based on the property of the WV channel as well as dynamics and thermodynamics of the dry intrusion extracted from numerical modeling data. It is first setup by Anthony J. Wimmers et al. [9-11] and Yann Michel [12,13]. The method proposed by Wimmers et al. is tested with GOES geostationary satellite data and NCEP GFS numerical forecasting by considering the relation between the dry intrusion and moisture. While, Michel's method is setup based on the relation between the dry intrusion and potential vorticity (PV) and is tested with MSG geostationary satellite data and ECMWF forecasting. Although both of them are proven to be optimized than the previous methods, it is found that their methods are based on the hypothesis that the dry intrusion is occurred under a complete dry atmosphere circumstance. So that the diabatic heating is ignored in the calculation of the physics parameters related to the dry intrusions in their methods. This hypothesis is often found to be questionable for the dry intrusions associated with rainstorms and some other severe convective weather due to the non-saturation state of air parcels under these circumstances.

Therefore, an improved combination method based on satellite and numerical forecasting for detecting dry intrusions associated severe convective weather is developed in this study. It will be 
The 1st International Electronic Conference on Atmospheric Sciences (ECAS 2016), 16-31 July 2016;

Sciforum Electronic Conference Series, Vol. 1, 2016

tested with FengYun-2 geostationary satellite and NCEP/GFS numerical data. This paper is organized as follows. In Section 2, the new method raised in this study is briefly described. And a validation and two typical case studies are used to evaluate the new method in Section 3. Then the paper is concluded in Section 4 with a summary and concluding remark.

\section{Methods}

The whole algorithm consists of 3 parts: the upper-tropospheric moisture retrieval, segmentation, and optimized adjustment.

\subsection{Upper-Tropospheric Moisture Retrieval}

For the upper-tropospheric moisture retrieval, it is based on the function of the upper-level moisture and brightness temperature of WV channels suggested by Soden and Bretherton [14]. The formula is shown as follows:

$$
\ln \left(\frac{\mathrm{RH}}{\cos \theta}\right)=\mathrm{a}-\mathrm{b} \cdot \mathrm{T}_{6.7}
$$

where $\mathrm{RH}$ is the relative humidity and $\mathrm{T} 6.7$ is the brightness temperature of $\mathrm{WV}$ channel of Fengyun-2E geostationary satellite (the center wave length is $6.7 \mu \mathrm{m}$ ), and $\theta$ is the zenith angle of satellite, a and $\mathrm{b}$ is the constant numbers.

According to the Clausius-Clapeyron equation, the relative humidity can be rewritten as:

$$
\mathrm{RH}=\mathrm{q} \cdot\left(\frac{1}{\varepsilon} \cdot \frac{\mathrm{P}_{\mathrm{d}_{0}}}{\mathrm{E}_{\mathrm{s}}\left(\mathrm{T}_{0}\right)}\right) \cdot \exp \left(-\lambda \frac{\mathrm{T}-\mathrm{T}_{0}}{\mathrm{~T}_{0}}\right)
$$

where $\mathrm{q}$ is the moisture mixing ratio, $\lambda$ is constant, $\mathrm{P}_{\mathrm{d}_{0}}$ and T0 are the reference pressure and temperature in troposphere which are set to $400 \mathrm{hPa}$ and $240 \mathrm{~K}$ [15]. $\varepsilon=\frac{R_{d}}{R_{v}}$ where $R_{d}=287.05 \mathrm{~J}$. $\mathrm{kg}^{-1} \cdot \mathrm{K}^{-1}, \mathrm{R}_{\mathrm{v}}=461.5 \mathrm{~J} \cdot \mathrm{kg}^{-1} \cdot \mathrm{K}^{-1}$ represent the specific gas constant for dry air and moisture respectively.

Based on the above equations, the upper-tropospheric moisture [16] can be written as:

$$
\mathrm{q}=\exp \left[\mathrm{c}_{0}+\mathrm{c}_{1}\left(\mathrm{~T}_{6.7}-\overline{\mathrm{T}}-\mathrm{c}_{2} \cdot \ln (\cos \theta)+\mathrm{T}_{0}\right)\right]
$$

where, c0, c1 and c2 are constants which are set as 5.964, -0.063 and 8.9 respectively, $\bar{T}$ is the weighted average of the temperature at $300 \mathrm{hPa}, 400 \mathrm{hPa}$ and $500 \mathrm{hPa}$. Figure 1 shows the comparison of the original satellite image and its corresponding retrieval specific humidity at upper troposphere by using the above equations. It is noticed that the dark areas in the WV channel image (Figure 1a) well correspond to the areas with low moisture in the upper-level moisture map (Figure 1b).

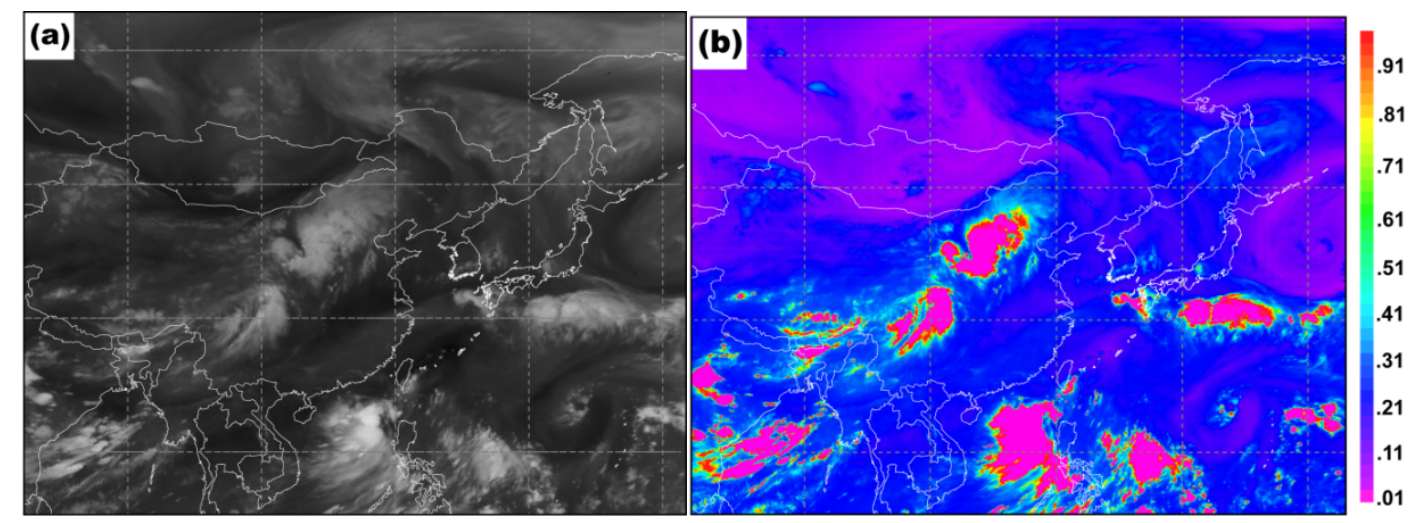

Figure 1. (a) FY2E WV channel image at 0000UTC July 21, 2012; (b) the corresponding retrieval specific humidity at upper troposphere $(\mathrm{k} / \mathrm{kg})$. 
The 1st International Electronic Conference on Atmospheric Sciences (ECAS 2016), 16-31 July 2016; Sciforum Electronic Conference Series, Vol. 1, 2016

\subsection{Segmentation}

According to the previous studies, during the air parcels travel upward to the uppertroposphere/lower-stratosphere the moisture content of the air parcels will decrease. This property makes the moisture as a good tropospheric tracer. On the other hand, it is found that most part of ozone reside in the stratosphere. Ozone is always regarded as a stratospheric tracer. The potential vorticity is considered conserve when neglecting friction and diabatic heating. It is often found to have a large value but a small value within stratosphere and troposphere respectively which makes the potential vorticity as a key parameter for detecting dry intrusion from stratosphere. Therefore, based on the results obtained in the 2.1 Section, the properties of the moisture, ozone and potential vorticity are used together to separate the air from troposphere against that from stratosphere on satellite images in this study.

As documented above, the air parcels are always in state of non-saturation under the circumstances of rainstorm and some other severe convective weather which means the air in the dry intrusions associated with those weathers could not be complete dry [17]. So the conservation of the Ertel potential vorticity which is only valid for dry air will not be valid under such conditions. While the general moisture potential vorticity which proposed by Gao et al. [18] is proven to have the ability to be generally used for all the conditions by using a condense ratio function in the Ertel potential vorticity equation. The equation is shown as Equations (4) and (5) as follows:

$$
\begin{gathered}
\theta^{*}=\theta \exp \left[\frac{\mathrm{L}}{\mathrm{c}_{\mathrm{p}}} \frac{\mathrm{q}_{\mathrm{s}}}{\mathrm{T}}\left[\frac{\mathrm{q}}{\mathrm{q}_{\mathrm{s}}}\right]^{\mathrm{k}}\right] \\
\mathrm{P}_{\mathrm{m}}=\alpha \zeta_{\mathrm{a}} \cdot \Delta \theta^{*}
\end{gathered}
$$

where, $P_{m}$ is the general moisture potential vorticity, $\zeta_{a}$ is the absolute vorticity, $\alpha$ and $\Delta \theta^{*}$ are the specific volume and static stability respectively.

Figure 2 shows the moisture distribution as a function of the general moisture potential vorticity and ozone respectively based on the statistic of 3.8 million samples randomly obtained from ECMWF Interim dataset which covering different seasons in year 2008. The samples of air parcels are grouped into three types which come from troposphere, the mixing zone of troposphere and stratosphere, and the stratospheric area. The criterion for the classification is based on the Equation (6).

$$
\left\{\begin{array}{ccc}
\mathrm{H}>\widetilde{\mathrm{H}}_{\max } & \left.\widetilde{\mathrm{H}}_{\max }=\max <\mathrm{H}_{\mathrm{d}}, \mathrm{H}_{\mathrm{t}}>\right) & \text { Stratosphere } \\
\widetilde{\mathrm{H}}_{\min } \leq \mathrm{H} \leq \widetilde{\mathrm{H}}_{\max } & \left(\widetilde{\mathrm{H}}_{\max }=\max <\mathrm{H}_{\mathrm{d}}, \mathrm{H}_{\mathrm{t}}>,\right. & \left.\widetilde{\mathrm{H}}_{\text {min }}=\min <\mathrm{H}_{\mathrm{d}}, \mathrm{H}_{\mathrm{t}}>\right) \text { UT } / \text { LS } \\
\mathrm{H}<\widetilde{\mathrm{H}}_{\min } & \left(\widetilde{\mathrm{H}}_{\min }=\min <\mathrm{H}_{\mathrm{d}}, \mathrm{H}_{\mathrm{t}}>\right) & \text { Troposphere }(<400 \mathrm{hPa})
\end{array}\right.
$$

It can be seen from Figure $2 a, c$ that both the relations between the potential vorticity and moisture and that between ozone and moisture taking a " $\mathrm{L}$ " pattern and show a weak timedependence which means that a solid negative correlation between these three elements can be found in all year around. To be further, a probability distribution analysis is made for getting a typical distribution patterns between potential vorticity and moisture and that between ozone and moisture. As shown in Figure $2 b, d$, the blue dots represent the samples with the probability under $1 \%$ and the yellow dots denote those having the probability of $1 \%-10 \%$. The orange and red dots are those with the probability of $10 \%-50 \%$ and over $50 \%$. A regression is made for those samples having probability over $1 \%$. The regression functions of potential vorticity and moisture and that of ozone and moisture are shown as formula (7) and (8) respectively (the confidence level of these two regressions are $94 \%$ and $88 \%$ respectively).

$$
\begin{gathered}
\mathrm{Y}=12.40310546 \cdot \mathrm{e}^{(-13.81471572 \mathrm{X})} \\
\mathrm{Y}=-147.4663656 \cdot \ln (\mathrm{X})-170.9865546
\end{gathered}
$$

So based on the regression functions, the moisture threshold for stratospheric air can be set at $0.0808 \mathrm{~g} / \mathrm{kg}$. And then the dry intrusion from stratosphere can be preliminarily detected on the satellite images. 

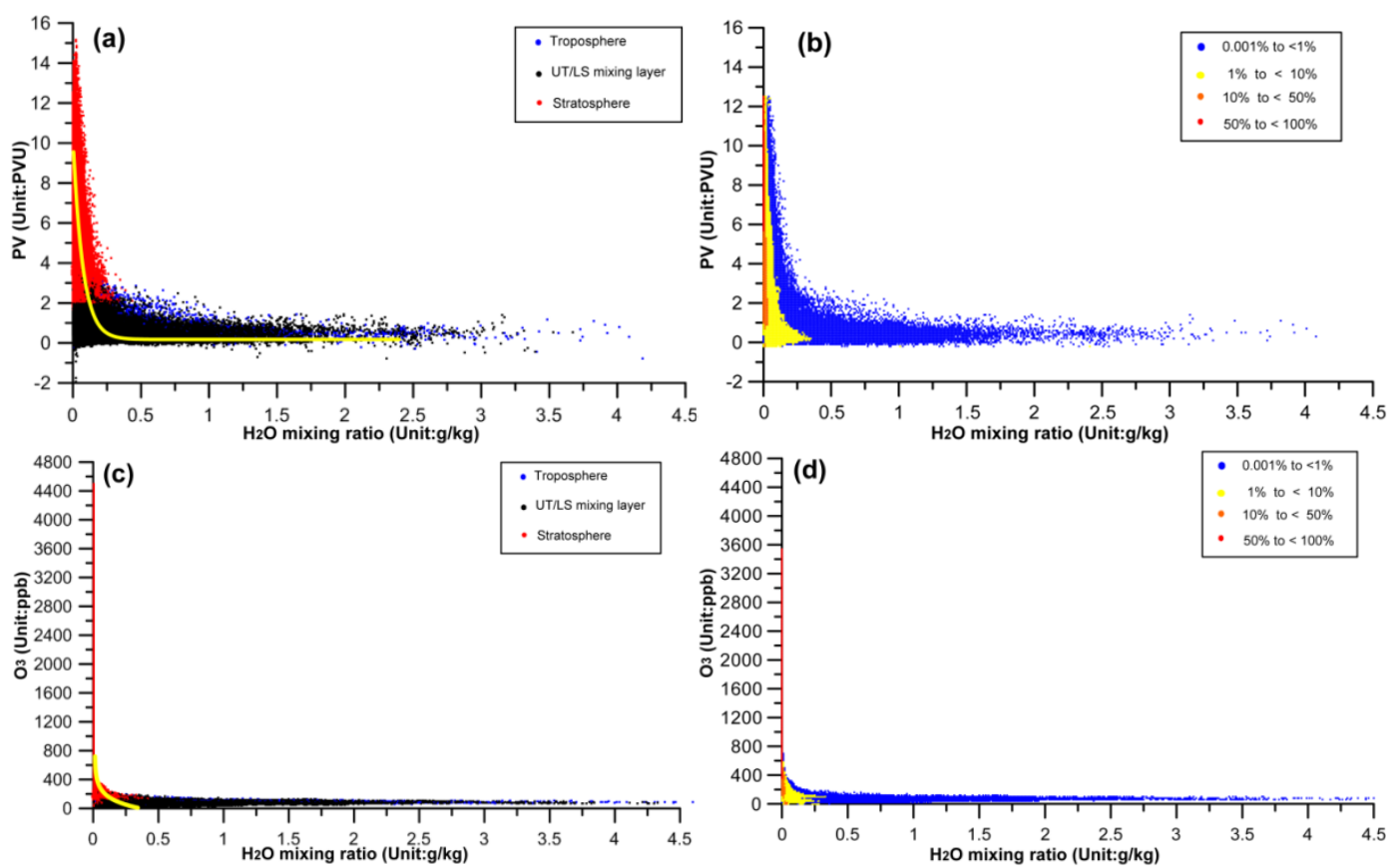

Figure 2. (a,b) Distribution and occurrence probability of the isentropic general moist potential vorticity and moisture from upper troposphere (over $400 \mathrm{hPa}$ ) to stratosphere; (c,d) same as (a,b) but for the ozone and moisture. (The red, blue and black points in figure $(\mathbf{a}, \mathbf{c})$ indicate air mass come from stratosphere, upper troposphere and mixing area between upper troposphere and lower stratosphere, the yellow curves are the fitting curves; The blue, yellow, orange and red points in figure $(\mathbf{b}, \mathbf{d})$ represent air masses occurrence probability lower than $1 \%$ and between $1 \%-10 \%, 10 \%-50 \%$ and over $50 \%$ ).

\subsection{Optimized adjustments}

To accurately recognize the dry intrusion, two optimized adjustments are used in this study. The first adjustment is to use the climatological dynamic tropopause height. The idea of using climatological dynamic tropopause height is inspired by Bak et al. [19] who use a climatological ozone profiler to improve the retrieval of the ozone within upper-troposphere/lower-stratosphere region. Following their idea, the climatological tropopause height is used here to compare with current tropopause height. If an area which is recognized as a dry intrusion area using the above two steps whose current tropopause height is lower than the climatological one, then the area will be keep as a potential dry intrusion area otherwise it would be removed.

It was documented by many studies that dry intrusion has a closed relation with upper-level jets. It is first found by Reed [20] during the study of the polar-frontal jets. So upper-level jets are selected as the second criterion for the optimized adjustment in this study. Although it is known a dry intrusion always associated with an upper-level jet, the spatial correlation between each other is unknown. Thus a statistical analysis of the spatial correlation of the dry intrusion and upper-level jets is made. Normally, an upper-level jet is axisymmetric system which means we can use its major axis to represent the position of the upper-level jet [12]. To extract the major axis of an upper-level jet a morphological image processing method, OPTA skeleton extraction[21] is used. Figure 3 is shown as an example by using the OPTA skeleton extraction to get the major axes of upper-level jets. It can be seen the location of upper-level jets is well represented by their axes. 
The 1st International Electronic Conference on Atmospheric Sciences (ECAS 2016), 16-31 July 2016; Sciforum Electronic Conference Series, Vol. 1, 2016
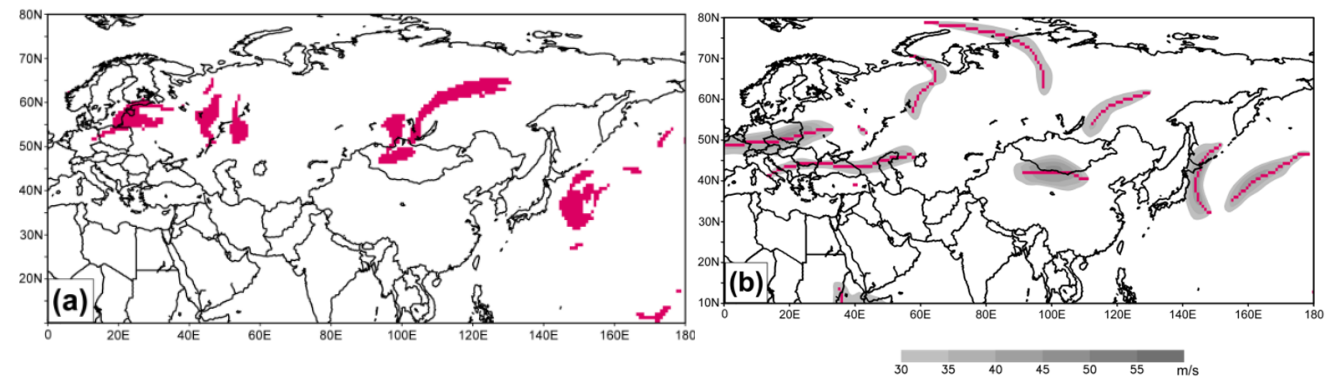

Figure 3. Upper level jetsover $350 \mathrm{~K}$ isentropic surface (shadings, unit:m/s) at 0000UTC 20 July 2012 with their corresponding axises (red solid lines).

Based on that, the occurrence probability of the dry intrusion within the range of 0-1000 km away from upper-level jets at $340 \mathrm{~K}, 345 \mathrm{~K}, 350 \mathrm{~km}$ and $355 \mathrm{~K}$ isentropic surfaces are calculated. It is noticed that the mean occurrence probability is about 0.15 while it will increase when the distance is no more than $300 \mathrm{~km}$ (Figure 4). By using this criterion, dry intrusions that occurred within $300 \mathrm{~km}$ away from upper-level jets will be kept. And the depth of dry intrusion is assigned as the height of 2 PVU.
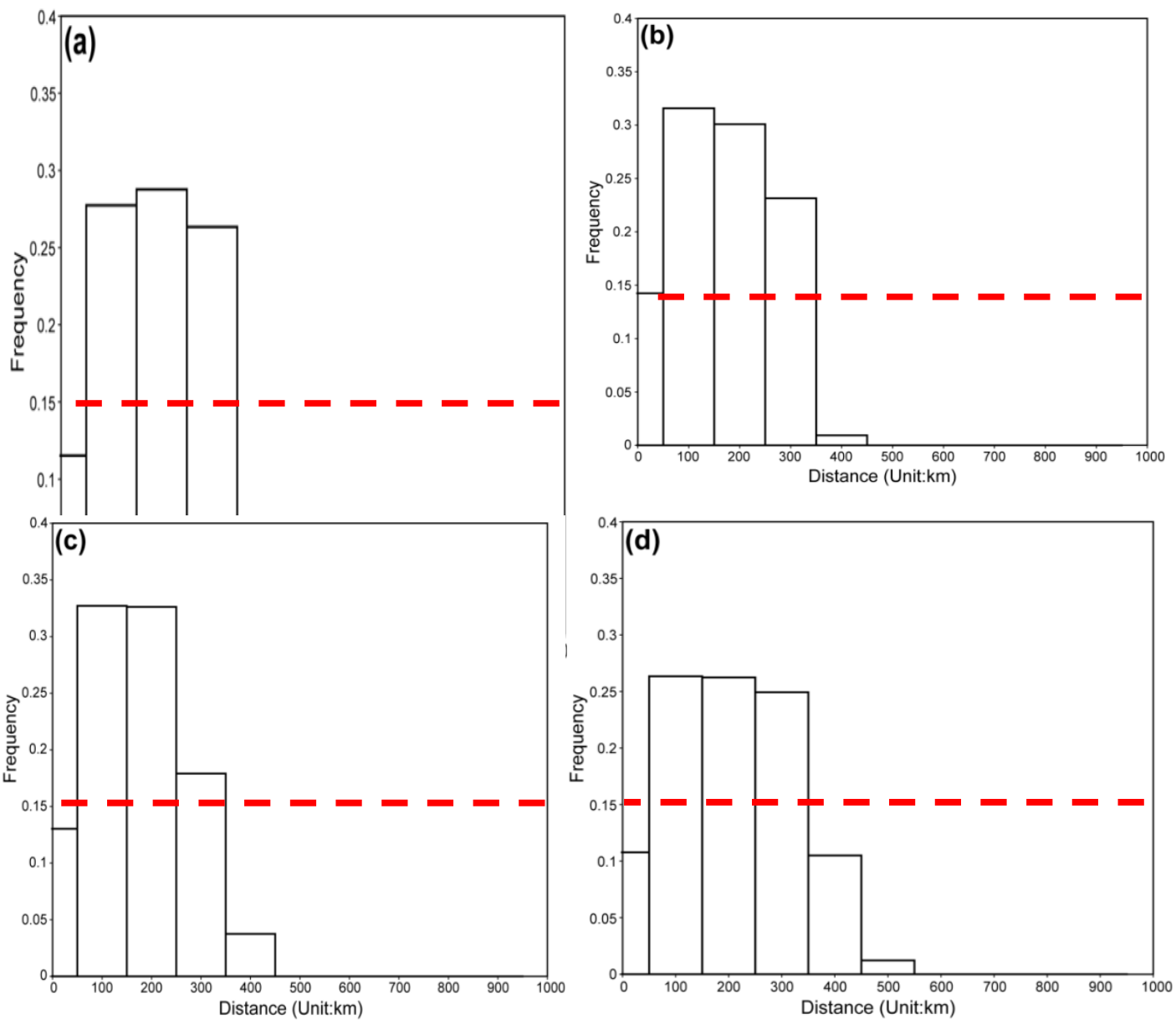

Figure 4. Frequency distribution of distances between Tropopause foldings and jet axes at $340 \mathrm{~K}-355$ $\mathrm{K}$ isentropic surfaces with $5 \mathrm{~K}$ interval (a:34 K;b:345 K;c:350 K;d:355 K) (horizontal and vertical coordinate denote distance and frequency distribution correspondingly). 
The 1st International Electronic Conference on Atmospheric Sciences (ECAS 2016), 16-31 July 2016; Sciforum Electronic Conference Series, Vol. 1, 2016

\section{Results}

\subsection{Validation}

The new method for detecting dry intrusion described in this study is validated by using some indirect observations. The ozone profiler retrieved from Fengyun-3B is used to compare with the dry intrusions. Figure 5 is an example that a dry intrusion is occurred. It can be seen that the ozone profiles retrieved by Fengyun-3B observe an elevation of the ozone concentration at about $200 \mathrm{hPa}$ at $\left(49^{\circ} \mathrm{N}\right.$, $108^{\circ} \mathrm{E}$ ) where dry intrusion is also detected by our new method. The lowest boundary of the dry intrusion estimated by our method at that place is about $350 \mathrm{hPa}$ which is not well consistent with the observation by Fengyun-3B. This discrepancy could be partly owed to the relative coarse vertical resolution of the ozone profiles retrieved by Fengyun-3B which has only 5 layers below $200 \mathrm{hPa}$.
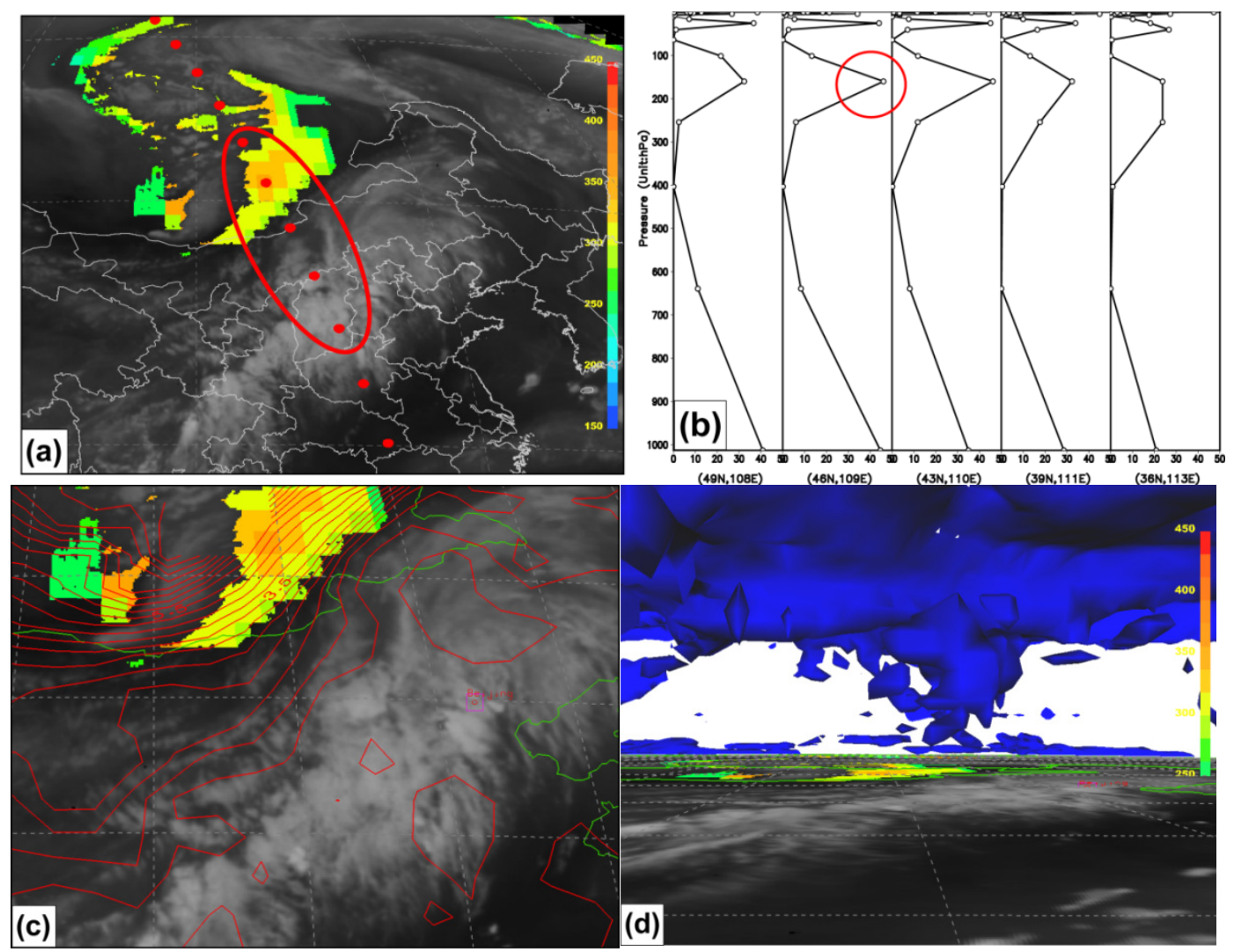

Figure 5. (a) The lowest boundary of Dry intrusion (hPa) at 0500UTC 21 July 2012 with the scanning trace of FY3B Solar Backscatter Uptraviolet Sounder at 0456UTC July 21,2012 (red points); (b) the ozone profiles (unit: DU) of the 5 points circled by the red cures in Figure $5 \mathrm{a}$.

Another evidence is found on the 3-D potential vorticity map calculated by using NCEP FNL data. As Figure $5 \mathrm{~d}$ shows, a positive potential voriticity column extends from the upper level to the lower level where dry intrusion is detected which indicates air parcels from stratosphere penetrate into troposphere over this area.

Since the aim of developing the new algorithm in this study is to use to detect the dry intrusion related to severe weather process such as rainstorm and some other convective events, two typical mid-latitude disastrous weather processes are selected for further evaluation. The two weather events selected in this study are the heavy rainstorm event occurred in Beijing on 21 July 2012 and a hailstorm event occurred in Zhejiang province in China on 19 March 2013. 
The 1st International Electronic Conference on Atmospheric Sciences (ECAS 2016), 16-31 July 2016; Sciforum Electronic Conference Series, Vol. 1, 2016

\subsection{Case I: A Rainstorm Event}

The heavy rainstorm event occurred in Beijing on 21 July 2012 is reported as the heaviest rainfall in the history of Beijing since 1950. The rainfall makes mud-rock flows and urban waterlog which bring a great loss in human life and property. Figure 6 shows the precipitation during that period. From the figures we can see that the precipitation is concentrated at the east part of the city with the center locating on the southeastern. Besides, both the variations of the mean precipitation and extreme one of the center area shown as Figure $6 b$ and $6 c$ suggest that the life time of the heavy precipitation is about 8-9 h during which 4 short-term fluctuations with an interval of 3 hours are observed. These characteristics together indicate that this heavy rainfall event is closed related to meso-scale weather systems.
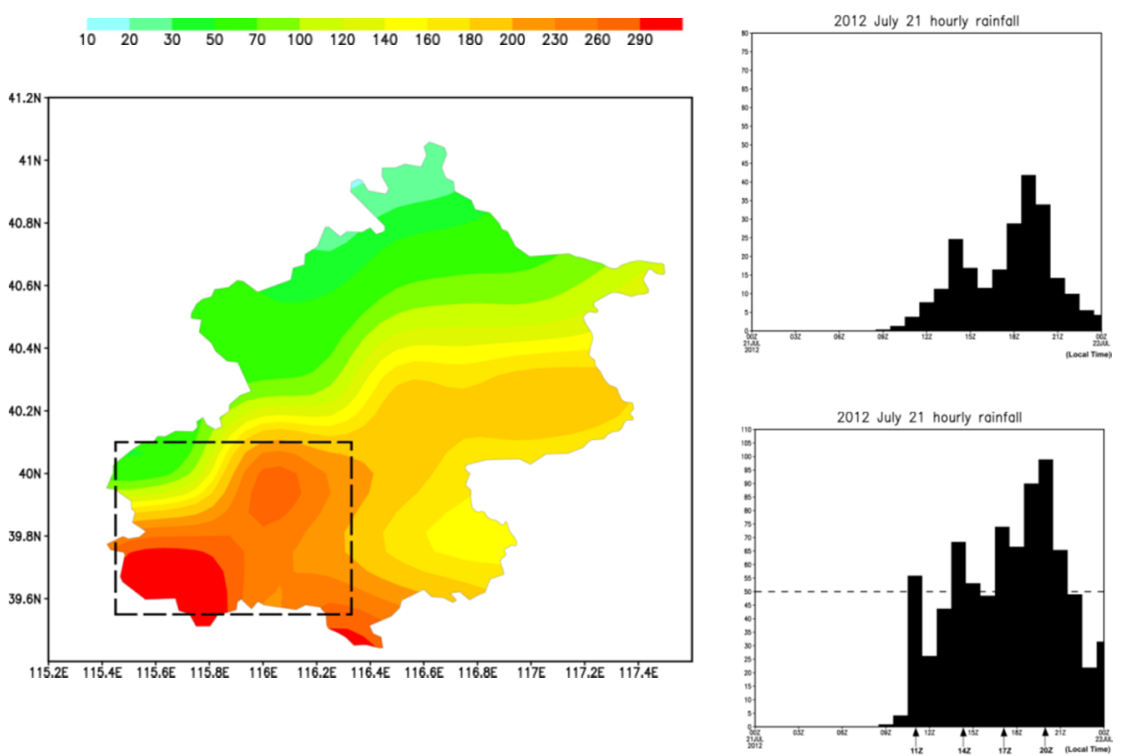

Figure 6. Observed precipitation over Beijing on July 21, 2012. (a) the horizontal distribution of the total rainfall during 08:00LST 21 July-08:00LST 22 July 2012 (unit:mm); (b) time evolution of the areaaveraged rainfall within the black dash rectangle in Figure 6a; (c) time evolution of the maximum rainfall observed in the dash rectangle area (Unit:mm).

According to the synoptic features, the rainstorm was occurred accompanied with a synoptic frontal cyclone. Meanwhile, two tropical storms "Vicente" and "Khanun" were generated in the northwest Pacific which supplied plenty moisture to the precipitation area from south and east. It was noticed that in the earlier stage of the rainfall, although the moisture is plentiful for the precipitation area, the intensity of rainfall is relatively weak due to the lack of cold dry air. So to track the dry air and evaluate their impact on this heavy precipitation event, the dry intrusion analysis using our new method is made.

Figure 8 shows the time evolution of the dry intrusion during the heavy precipitation event. It can be seen that a region of dry intrusion was occurred to the west of the precipitation area about 12 hours before the heavy rainfall occurs (Figure 8a). The maximum of the dry intrusion at that time was located apart from the center of the cold advection. After that this area was observed move southeastward closed to the center of the cold advection at middle level at 14:00LST when the rainfall began to increase (Figure 8b). At 20:00LST when the precipitation reaches the maximum, the location of the maximum of dry intrusion is observed to be consistent with that of the cold advection at middle level. In this case, the cold dry air from upper-level confront with the warm moist air at lower level at the boundary of the cold-warm advection thus inducing a southwest-northeastward rain band (Figure 8c). During the dissipation stage, a split was occurred on the original dry intrusion area. The 
The 1st International Electronic Conference on Atmospheric Sciences (ECAS 2016), 16-31 July 2016;

Sciforum Electronic Conference Series, Vol. 1, 2016

south part continued moving northeastward with the cold advection at middle level which corresponds to the northeastward movement of the precipitation area. Thus it can be seen that the occurrence of the dry intrusion is a key factor to trigger the heavy precipitation in this case.
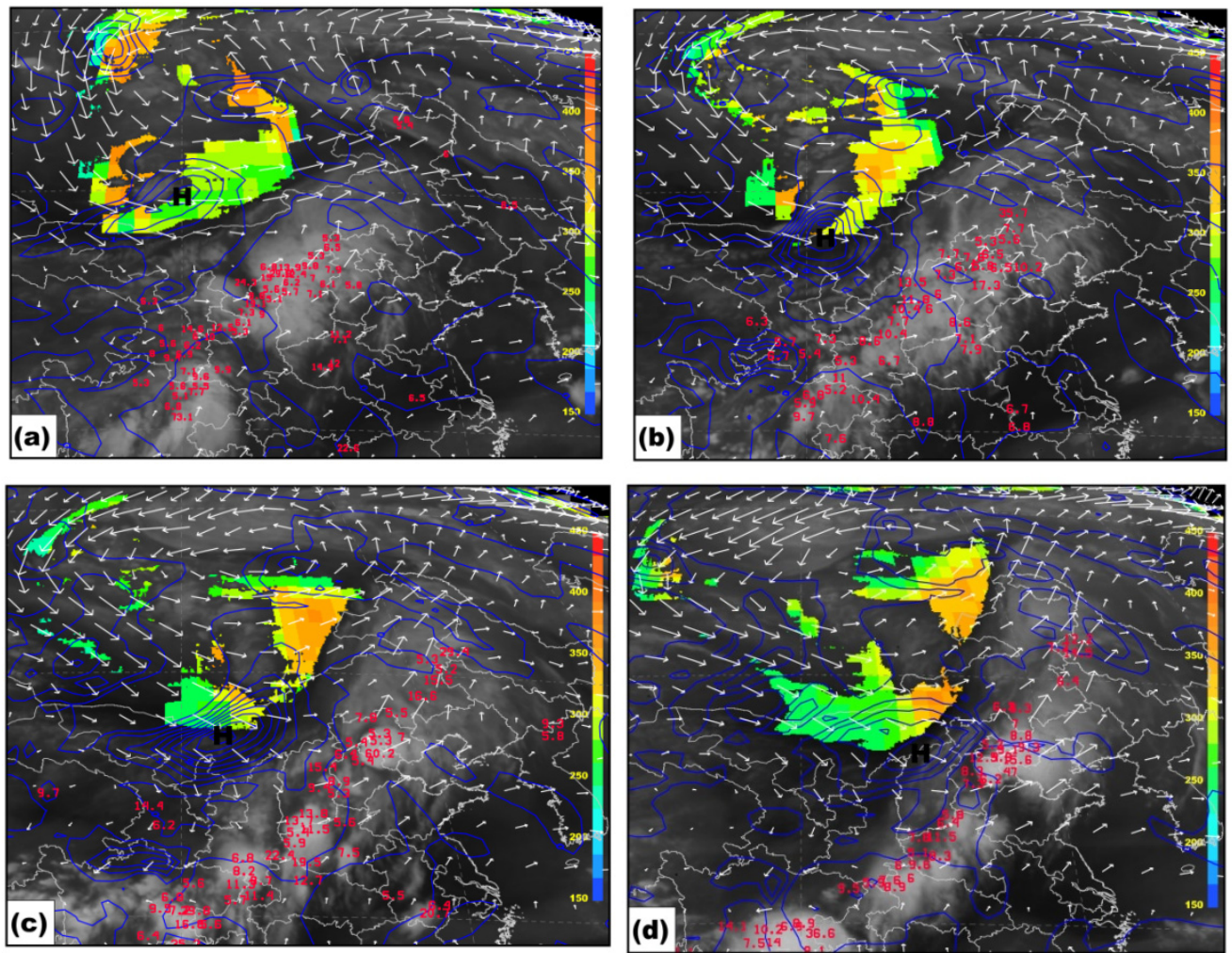

Figure 6. Dry intrusion (color shaded) composited by FY2E WV channel images, cold advection (blue thick line) and wind(white vector) at $320 \mathrm{~K}$ isentropic and hourly rainfall (over $5 \mathrm{~mm}$, in red digital)

(a) 0800LST July 21; (b) 1400LST July 21; (c) 2000LST July 21; d)0200LST July 22, 2012.

\subsection{Case II: Hailstorm Event}

Another episode is a hailstorm event which occurred at Taizhou in Zhejiang province of China. Same as the first case, this case is also occurred in front of a cold front. According to the report, a wide spread rainstorm was occurred over Zhejiang, Jiangsu, Anhui and Jiangxi provinces before 16:00LST 19 March 2013. When the raincloud move eastward over mid-east of Zhejiang at about 16:00LST, it caused hailstorm instead of rainstorm over that area. The whole process lasted only 10 minutes and only a small area of Taizhou city was impacted by this hailstorm. Although it is short-term and quite regional the photos shown in Figure $7 \mathrm{~b}$ suggest that the intense of the hailstorm is quite impressive. So far, radar observations are widely used to monitor such kind of convective events. Nevertheless, forecasters still find tough in forecasting such kind of system since it is occurred in a short-term and small region. Therefore, it is curious to know if there are any other signs such as dry intrusions from upper-level troposphere can supply an early warning for such disastrous weather event.

Figure 8 shows the WV channel image composited by positive vorticity and detected dry intrusion $24 \mathrm{~h}$ before the hailstorm. It can be seen that an unobvious dry intrusion is occurred over southwest to north part of Zhejiang province with the lowest intrusion boundary reached to $400 \mathrm{hPa}$ over southeast part. To verify it, the TlnP where the maximum dry intrusion is detected is examined. It is encouraging to note that there are two dry layers which are located at $150 \mathrm{hPa}$ and $400 \mathrm{hPa}$ respectively which indicate the dry intrusion depth is well estimated. As documented by many studies, large quantity of energy is needed for the development of severe convective systems. CAPE and DCAPE which are two energy indices are usually used for measuring the energy related to 
The 1st International Electronic Conference on Atmospheric Sciences (ECAS 2016), 16-31 July 2016;

Sciforum Electronic Conference Series, Vol. 1, 2016

convective systems. CAPE is the convective available potential energy which often indicates the intensity of the upward motion while DCAPE is the maximum energy available to a descending parcel of air. Normally the higher the value of CAPE (DCAPE) is, the stronger the convection (downdraft) potential will be. It is showed that the CAPE and DCAPE over Taizhou at 16:00LST 18 March 2013 is about 0 and $300 \mathrm{~J} / \mathrm{kg}$ respectively which means both the convection at low-level and dry intrusion from upper-level are weak.
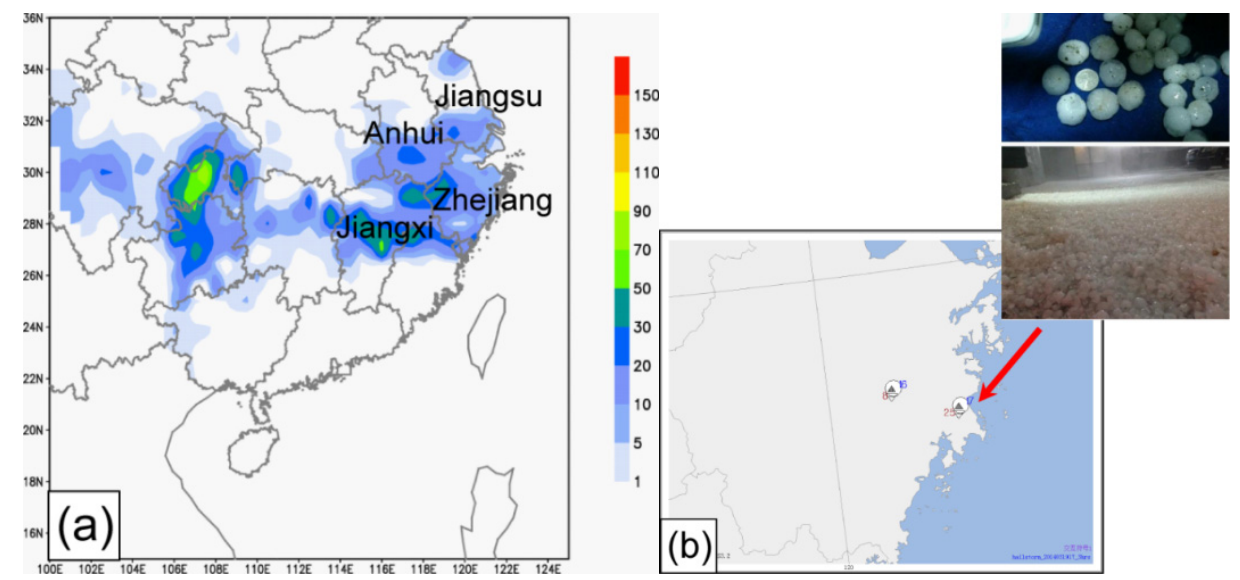

Figure 7. (a) The 24-h accumulated rainfall on 19 March, 2014; (b) Hailstorms observed at Taizhou city in Zhejiang province of China.

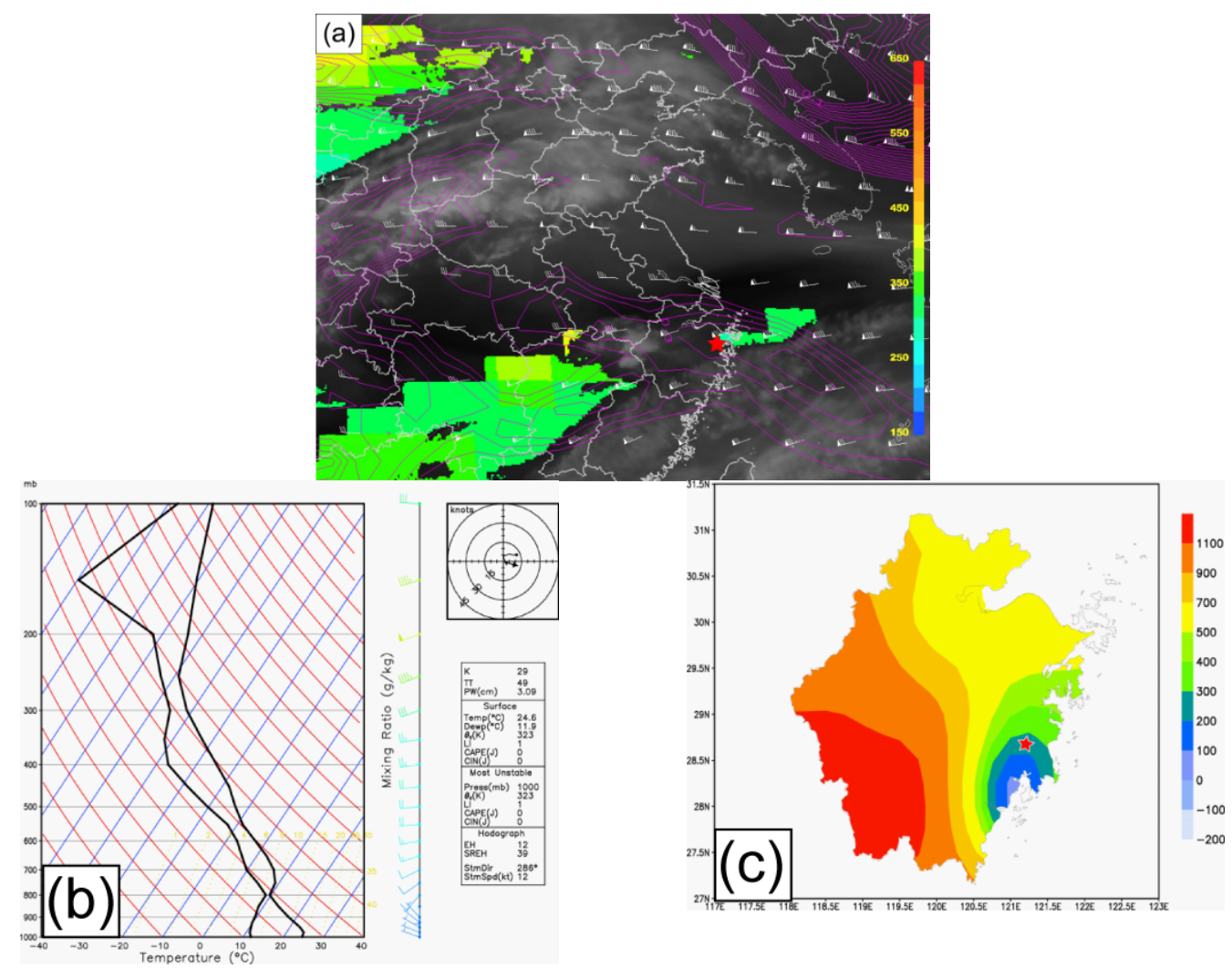

Figure 8. (a) The composition map of dry intrusion(shadings) and positive vorticity(contours, unit: $10^{-4} \mathrm{~s}^{-1}$ ) at $315 \mathrm{~K}$ isentropic layer at 16:00LST $18 \mathrm{Mar} 2014$; (b) T-lnP at the location shown with starisk in Figure 8a; (c) DCAPE distribution within Zhejiang province (The starisk denotes the location of Taizhou city). 
While 12 hours later (not shown), it is found both the area of dry intrusion over north part of Zhejiang expand and the intensity increase. The lowest boundary of the dry intrusion reaches to about $550 \mathrm{hPa}$ which is consistent with the position of dry layers observed in the T-lnP map. Besides, the CAPE and DCAPE at this time increase to $400 \mathrm{~J} / \mathrm{kg}$ and $400 \mathrm{~J} / \mathrm{kg}$ respectively. Figure 9 shows the dry intrusion 6 hours before the hailstorm. Although a reduction in the dry intrusion area over Zhejiang province is found, the lowest boundary of the dry intrusion drops down to about $700 \mathrm{hPa}$. Meanwhile, the positive vorticity at $315 \mathrm{~K}$ isentropic layer is observed to increase beneath the intrusion area with the maximum reaches $0.5 \times 10-4 \mathrm{~s}-1$. And the DCAPE experiences a sharp increase and around $1000 \mathrm{~J} / \mathrm{kg}$ while the CAPE still maintains at $400 \mathrm{~J} / \mathrm{kg}$ during this period. Typically, DCAPE values over $800 \mathrm{~J} / \mathrm{kg}$ are often significant and imply downward transport of higher momentum air to the surface. According to Hoskins's PV view [22], a high positive abnormal of PV transported downward by dry intrusion will increase positive vorticity which will trigger the development of a meso-scale cyclone at lower level. Therefore, from this perspective, dry intrusion may be a major contributor to the development of this hailstorm in Zhejiang. As expected, the dry intrusion disappeared when the hailstorm occurred (not shown). And when the hailstorm ceased, both of the CAPE and DCAPE drop steeply with the DCAPE value of $200 \mathrm{~J} / \mathrm{kg}$. Based on the above, we can see that the temporal and spatial variations of dry intrusion match with the hailstorm quite well. The early appearance of the dry intrusion over the hailstorm area can be seen as a pre-warning of such kind of convective weather.
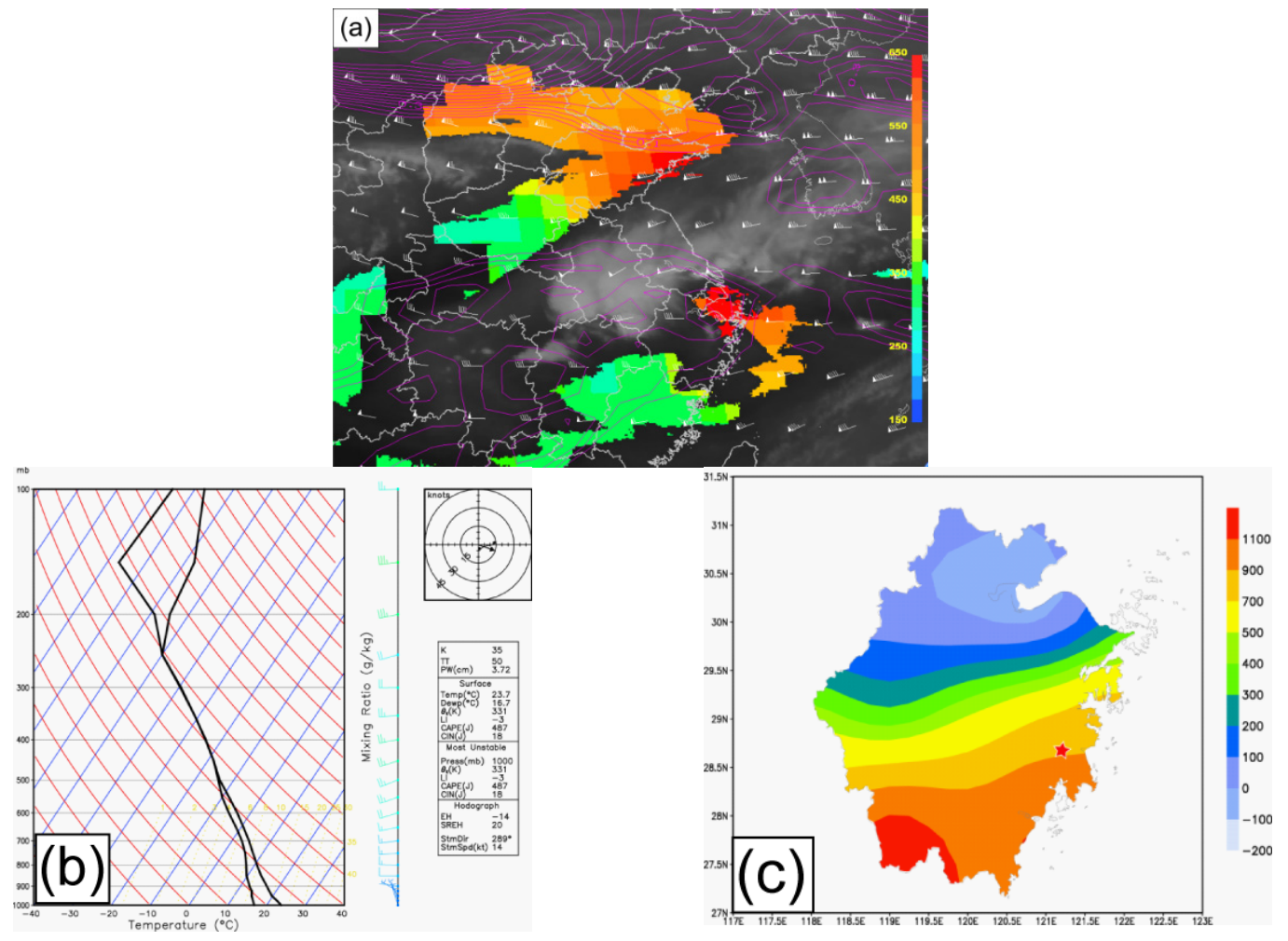

Figure 9. (a) The composition map of dry intrusion(shadings) and positive vorticity(contours, unit : $10^{-4} \mathrm{~S}^{-1}$ ) at $315 \mathrm{~K}$ isentropic layer at 10:00LST $19 \mathrm{Mar} 2014$; (b) T-lnP at the location shown with starisk in Figure 9a; (c) DCAPE distribution within Zhejiang province (The starisk denotes the location of Taizhou city).

\section{Conclusions}

Dry intrusion is an important phenomenon within the upper-troposphere and lowerstratosphere region. It is significant for the troposphere-stratosphere exchange, severe precipitation and some other disastrous weather. Due to its importance, several methods for detecting this 
The 1st International Electronic Conference on Atmospheric Sciences (ECAS 2016), 16-31 July 2016; Sciforum Electronic Conference Series, Vol. 1, 2016

phenomenon are set up. So far the methods of combining diagnosis and modeling are widely used and proven to be more efficient. However, all of them are built on the basis of the hypothesis of the dry atmosphere. This hypothesis to some extent will limit the range of the applications especially for those related to convective weather episodes. Therefore, an improved method which considering the moisture effect by using a general moisture potential voriticity is set up. In this method, statistical analyses are made to acquire the relation between satellite-retrieved upper-level moisture and modeling general potential voriticity and ozone. The method is tested by Fengyun-2E satellite data and ECMWF Interim data and validated by using Fengyun-3B observed ozone profiles and NCEP FNL analysis data. The applications of this method in two typical mid-latitude disastrous weather episodes occurred in China in 2012 and 2013 show that the method we developed in this study is applicable. It can be used in analyzing the development of various weather episodes such as rainstorm, severe convective weather such as hailstorm. Both cases show that dry intrusion may be a major contributor of these weather cases. It can be a supplementary index for helping forecaster to make a pre-warning for severe weather events if a more detailed statistics of the temporal and spatial relations between dry intrusion and severe weather are made.

Acknowledgments: This work was supported by the Chinese National Science Founding (NSFC) grants 41575048 and 41175023.

Author Contributions: In this work, Yi-Xuan Shou and Feng Lu designed all the algorithm and performed the experiments; Shaowen Shou contributed to the meteorological analysis of the disastrous weather events.

\section{References}

1. Shou, S.; Li, S.; Yao, X. Mesoscale Meteorology, 1st ed.; China Meteorological Press: Beijing, China, 2003. (In Chinese)

2. Reid, H.J.; Vaughan, G. Convective mixing in a tropopause fold. Q. J. R. Meteorol. Soc. 2004, 130, 1195-1212.

3. Nastrom, G.D.; Green, G.L.; Peterson, M.R.; Gage, K.S. Tropopause folding and the variability of the tropopause height as seen by the flatland VHF radar. J. Appl. Meteorol. 1989, 28, 1271-1281.

4. Bertin, F.; Campistron, B.; Wilson, R.; Caccia, J.L. Mixing processes in a tropopause folding observed by a network of ST radar and lidar. Ann. Geophys. 2001, 19, 953-963.

5. Roger, B.W.; Holmes, S.J. Water Vapor Imagery: Interpretation and Applications to Weather Analysis and Forecasting. NOAA Tech. Rpt., NESDIS 57,213; National Oceanic and Atmospheric Administration: 1991.

6. Lamarque, J.-F.; Hess, P.G. Cross-tropopause mass exchange and potential vorticity budget in a simulated tropopause folding. J. Atmos. Sci. 1994, 51, 2246-2269.

7. Bithell, M.; Gray, L.J.; Cox, B.D. A three-dimensional view of the evolution of midlatitudes stratospheric intrusions. J. Atmos. Sci. 1999, 56, 673-688.

8. Appenzeller, C.; Davies, H.C. Structure of stratospheric intrusions into the troposphere. Nature 1992, 358, 570-572.

9. Wimmers, A.J.; Moody, J.L.; Browell, E.V.; Hair, J.W.; Grant, W.B.; Butler, C.F.; Fenn, M.A.; Schmidt, C.C.; $\mathrm{Li}$, J.; Ridley, B.A. Coauthor, Signatures of tropopause folding in satellite imagery. J. Geophys. Res. 2003, 108, D4, 8360, doi:10.1029/2001JD001358.

10. Moody, J.L. Tropopause folding at satellite-observed spatial gradients: 1 . Verification of an emipirical relationship. J. Geophys. Res. 2004, 109, D19306, doi:10.1029/2003JD004145.

11. Moody, J.L. Tropopause folding at satellite-observed spatial gradients: 2. Development of an empirical model. J. Geophys. Res. 2004, 109, D19307,doi:10.1029/2003JD004146.

12. Michel, Y.; Bouttier, F. Automated tracking of dry intrusions on satellite water vapour imagery and model output. Q. J. R. Meteorol. Soc. 2006, 132, 2257-2276.

13. Data assimulation of tropopause height using dry intrusion observations. Mon. Weather Rev. 2010, 138, $101-122$.

14. Soden, B.J.; Bretherton, F.P. Interpretation of TOVS water vapor radiances in terms of layer-average relative humidities: Method and climatology for the upper, middle, and lower troposphere. J. Geophys. Res. 1996, 101, 9333-9343. 
The 1st International Electronic Conference on Atmospheric Sciences (ECAS 2016), 16-31 July 2016;

Sciforum Electronic Conference Series, Vol. 1, 2016

15. Soden, B.J.; Bretherton, F.P. Upper tropospheric relative humidity from the GOES 6.7 $\mu$ m channel: Method and climatology for July 1987. J. Geophys. Res. 1993, 98, 16669-16688.

16. Moody, J.L.; Wimmers, A.J.; Davenpor, J.C. Remotely sensed specific humidity: Development of a derived product from the GOES Imager Channel 3. Geophys. Res. Lett. 1999, 26, 59-62.

17. Gao, S.; Zhou, F.-F. Water vapour potential vorticity and its applications in Tropical cyclones. Chin. Phys. Lett. 2008, 25, 3830-3833.

18. Gao, S.; Wang, X.; Zhou, Y. Generation of generalized moist potential vorticity in a frictionless and moist adiabatic flow. Geophy. Res. Lett. 2004, 31, L12113.

19. Bak, J.; Liu, X.; Wei, C.; Pan, L.L.; Chance, K.; Kim, J.H. Improvement of OMI ozone profile retrievals in the upper troposphere and lower stratosphere by the use of a tropopause-based ozone profile climatology. Atmos. Meas. Tech. Discuss. 2013, 6, 4333-4369.

20. Reed, R.J. A study of characteristic type of upper level frontogenesis. J. Meteor. 1995, 12, 226-237.

21. Wu, J.; Zhang, G.; Xia, J.; Cui, Z.M. Research on cerebral aneurysm detection based on OPTA algorithm. In Proceedings of the 2009 International Symposium on Information Processing(ISIP'09), Huangshan, China, 2009; pp. 37-40.

22. Hoskins, B.J. Towards a PV- $\theta$ view of the general circulation. Tullus 1991, 43, 27-35.

(C) 2016 by the authors; licensee MDPI, Basel, Switzerland. This article is an open access article distributed under the terms and conditions of the Creative Commons by Attribution (CC-BY) license (http://creativecommons.org/licenses/by/4.0/). 